\title{
Produção de subjetividade pelas práticas do vestir no Brechó de Troca: novos campos para a Psicologia Social
}

Producción de subjetividad por las prácticas del vestir en el Brechó de Troca: nuevos campos para la Psicología Social

Production of subjectivity by the practices of dressing in the Brechó de Troca: new fields for Social Psychology

Helena de Barros Soares

ORCID: https://orcid.org/0000-0002-5803-142X

Universidade Federal do Rio Grande do Sul, Rio Grande do Sul/Brasil

\begin{abstract}
Declaração de Direito Autoral
A submissão de originais para este periódico implica na transferência, pelos autores, dos direitos de publicação impressa e digital. Os direitos autorais para os artigos publicados são do autor, com direitos do periódico sobre a primeira publicação. Os autores somente poderão utilizar os mesmos resultados em outras publicações indicando claramente este periódico como o meio da publicação original. Em virtude de sermos um periódico de acesso aberto, permite-se o uso gratuito dos artigos em aplicações educacionais e científicas desde que citada a fonte conforme a licença CC-BY da Creative Commons.
\end{abstract}

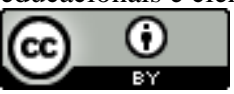

\section{Resumo}

O presente artigo mostra como o sistema da moda vem produzindo modos efêmeros de práticas do vestir calcadas no consumo frenético, a partir do olhar problematizador da relação do sujeito com a roupa enquanto produção de subjetividade. Se outrora a moda foi ferramenta para diferenciação de classes e setores sociais, hoje a produção de subjetividade implica em modos de parecer para ser. Tal efemeridade produz efeitos que a Psicologia Social pode ler como demanda para produção de projetos e modos de escuta de atuações já existentes. O projeto do Brechó de Troca é descrito como campo da Psicologia Social, de abordagem ético-estética e política. E um espaço de convívio onde o escambo é um chamariz para possíveis encontros, um grupo que resiste aos modos efêmeros de consumo de moda. $\mathrm{O}$ artigo mostra as condições de possibilidade para a criação do Projeto que, em janeiro de 2019 faz 10 anos de existência sempre resistindo aos recursos perversos do mercado de moda.

Palavras-chaves: Práticas do vestir; Moda; Produção de subjetividade; Brechó de troca.

\section{Resumen}

El presente artículo muestra cómo el sistema de la moda viene produciendo modos efímeros de prácticas del vestir calcadas en el consumo frenético, a partir de la mirada problematizadora de la relación del sujeto con la ropa como producción de subjetividad. Si alguna vez la moda fue herramienta para diferenciación de clases y sectores sociales, hoy la producción de subjetividad implica en modos de parecer para ser. Tal efemeridad produce efectos que la Psicología Social puede leer como demanda para la producción de proyectos y modos de escucha de actuaciones ya existentes. El proyecto del Brechó de Troca es descrito como campo de la Psicología Social, de enfoque ético-estético y político. Y un espacio de convivencia donde el escambo es un señuelo para posibles encuentros, un grupo que resiste a los modos efímeros de consumo de moda. El artículo 
muestra las condiciones de posibilidad para la creación del Proyecto que en enero de 2019 hace 10 años de existencia siempre resistiendo a los recursos perversos del mercado de la moda.

Palabras claves: Prácticas de vestir; Moda; Producción de subjetividad; Brechó de troca.

\begin{abstract}
The present article shows how the fashion system has been producing ephemeral modes of dress practices based on frantic consumption, from the problematizing view of the relation of the subject to the clothing as a production of subjectivity. If once fashion was a tool for differentiating classes and social sectors, today the production of subjectivity implies modes of opinion to be. This ephemerality produces effects that Social Psychology can read as a demand for the production of projects and ways of listening to existing actions. The Project of the Brechó de Troca is described as a field of Social Psychology, ethical-aesthetic and political approach. And a convivial space where the barter is a decoy for possible meetings, a group that resists the ephemeral modes of fashion consumption. The article shows the conditions of possibility for the creation of the Project that, in January of 2019, has been in existence for 10 years, always resisting the perverse resources of the fashion market.
\end{abstract}

Keywords: Practices of dress; Fashion; Production of subjectivity; Brechó de troca.

\section{Introdução}

As roupas e os adornos são elementos que protegem e cobrem o corpo, mas nossa relação com elas não se resume a isso. Em nossa sociedade urbana e ocidental, por exemplo, o nu é entendido como atentado ao pudor, sendo a ele reservado punição ou, raramente, a arte. É interessante pensar como os objetos ocupam uma função para o sujeito (e seus coletivos), como o produzem e se transformam. A moda, assim como a ideia de sujeito, se produz como conceito em um contexto específico. A relação com a roupa não podia ser entendida como moda até meados do século XVII, assim como não era possível entender os modos de subjetivação por um viés individualizante ou da singularidade. De sua invenção até os dias de hoje a moda transformou-se em um sistema efêmero de produção incessante: o excesso de consumo de moda expressa um tipo de produção de subjetividade em que o sujeito empresta seu desejo a serviço de um modo capitalístico de manutenção do mercado de consumo.

Os efeitos da mutação do sistema da moda, que parte da distinção social (Bourdieu, Delsaut, 2001) como modelo, passando ao parecer como novo modo de ser (Maffesolli, 2010) são a aceleração do consumo, a (des)implicação dos sujeitos para com os objetos que consome e o aumento expressivo do descarte alienado de roupas.

Que olhares, escutas e práticas, a Psicologia Social é capaz de ter a partir deste cenário? O que pode um profissional da Psicologia fazer neste processo? A partir da curiosidade sobre este campo e me entendendo uma psicóloga que se subjetivou no universo das roupas, produz um projeto cunhado de Brechó de Troca e, com ele, penso proposições metodológicas que sustentem um espaço-tempo para exercícios de si, práticas do vestir que sejam capazes de produções de subjetividade pela roupa de modo singularizante, plural. Este artigo é um relato profissional de um trabalho que já dura 10 anos de experiência. Pretendo apontar que a moda produz um sujeito tanto quanto o inverso, e que isto é visível a partir de traçado histórico não linear, tal qual a perspectiva foucaultiana de uma historicidade descontínua. Mostra ainda que o engendramento de práticas perversas de consumo de moda inquieta o olhar da psicóloga, buscando a desnaturalização e discussão de tais práticas, e que se implica e produz uma ação. $O$ texto 
descreve brevemente as condições de possibilidade para a criação do Brechó de Troca, explica sua metodologia e explica porque ela mantém-se com algumas poucas modificações. Ainda cita, brevemente, algumas experiências que pontualmente expressam e justificam sua existência. A ideia é lembrar que sem parcerias, ampliação de seus limites e abertura as críticas o trabalho não teria resistido sempre exercitando brechas para as práticas de vestir no contemporâneo.

\section{Moda e Sujeito: efeitos contemporâneos destas invenções}

As peças que são usadas sobre o corpo, se prestam a proteger e adornar, mas a tensão entre a exibição do adorno e a preocupação com a proteção, análogas ao mal-estar na civilização descrito por Freud em 1930, desestabilizam figuras constantes e denominase moda (Flügel, 1964). Mas em algumas sociedades o uso da indumentária presta-se para diferenciar diferentes clãs; esse recurso ainda é válido em algumas culturas, mas no passado era uma constante em diferentes lugares. Tal descrição diferencia-se do conceito de moda. Leventon (2009) descreve como na sociedade romana, por exemplo, a indumentária presta-se a diferenciação de classes.

A sociedade romana era muito estratificada, e o vestuário era um aspecto importante no estabelecimento e na manutenção da hierarquia. A posição de um indivíduo podia ser identificada por uma grande variedade de fatores, como a qualidade dos materiais, o tipo, o tamanho e as cores das roupas, além da forma como eram vestidas. Era comum, por exemplo, os soldados romanos usarem túnicas mais compridas que as dos homens civis. Os escravos, por outro lado, podiam ser identificados pelos calçados, ou pela ausência deles, já que eram proibidos os calcei, sapatos romanos de cano alto. (p. 31)
Não só lá, mas em diversas culturas, em diferentes épocas, as roupas ou indumentárias prestaram-se para marcar de modo claro e, muitas vezes brutal, a diferença social dos grupos, seja por questões econômicas, raciais, étnicas, religiosas ou de gênero. São jogos de poder que se vão produzindo usando a roupa e demais adornos como recursos para visibilizar certas práticas. No ocidente tais diferenças mantiveram-se com certa estabilidade até o final da Idade Média (Calanca, 2008).

Até então não era possível representar a imagem de forma detalhada; não havia técnicas de pintura que possibilitassem expressar quais tecidos estavam sendo utilizados, que cores eram possíveis de serem produzidas com técnicas de tingimento, ou detalhes da forma das roupas nos corpos. A arte só passou a ter técnicas que possibilitavam tal precisão de representação em meados do século XVII; com este advento foi possível tanto a representação de práticas como o afinco de superá-las. Com o advento da burguesia, inventou-se uma parcela da população que poderia competir com a nobreza no quesito de bens, até superando-os. Mas ainda com papeis definidos, pois aos reinados eram restritas certas práticas ostentarias, à aparência era reservada certa estabilidade. Um nobre apareceria em uma representação pictórica com suas joias, ao passo que um burguês desejaria mostrar suas peles. As mudanças sociais acarretadas, dentre muitos elementos, pelo processo de colonização, possibilitaram a entrada de tecidos mais elaborados e tinturas mais expressivas no território europeu. Passou a ser cada vez mais difícil à nobreza mostrar, através da aparência, sua diferença social e impor-se perante súditos, pois passou a ser mais fácil copiar elementos de aparência. Entre 1485 e 1660 foram produzidos dezoito decretos, ou leis suntuárias, que restringiam o uso de tecidos, cores, formas para o vestir. "A legislação ecoava os tratados; as leis suntuárias atacavam os mecanismos de 
registro do mimetismo social." (Roche, 2007, p.62).

A partir da crise das instituições da Idade Média, não substituídas por outras no Renascimento, começa-se a valorização do indivíduo na centralidade das coisas (Figueiredo; Santi, 2002). No processo de individualização do sujeito, de invenção de uma subjetividade privatizada que se passa a produzir novas formas de se ser e de se desejar costuradas a existência de uma lógica de moda mais dinâmica.

No transcurso da modernidade, a França, desde o reinado dos Luíses, seguiu ditando o modo de como vestir-se. A preocupação francesa em manter-se esteticamente distinta do restante do mundo ganha uma maior proporção a partir da segunda metade do século XIX, refletindo-se na manutenção da Câmara Sindical de Costura Parisiense. São criados critérios de excelência para diferenciação, dificílimos de serem reproduzidos. Nem mesmo a guerra impediu que a entidade exigisse de seus associados altos padrões de qualidade e criatividade. É neste ínterim de polêmicas, em que se debatia o que era possível seguir mantendo, em que se exibe o luxo das produções das maisons, de um lado, e a crise financeira do pós-guerra, de outro, que se inventa o prêt-à-porter: uma resposta à crise da haute couture que vinha oferecer modelos prontos para vestir, bem elaborados e com simplicidade técnica na confecção. Copiadores dos modelos frequentavam desfiles para conhecer cada nova peça inventada a fim de divulgá-las mundo afora. Os modelos divulgados na mídia davam, às mais longínquas populações, o acesso às imagens de um vestir europeu do pós-guerra e suas décadas seguintes (Lipovetsky, p.69-105). Neste período passa a se potencializar a ideia de novidade como condição para sustentar a mudança do mercado de moda. A moda passa de uma produção voltada para os adultos a moda para a juventude.
Michel Foucault, conhecido também como historiador da descontinuidade, tinha olhar voltado aos processos, nos campos que pesquisou. No caso desta descrição histórica que faço aqui, busco apontar que, até certo momento histórico europeu, a efemeridade das mudanças nos modos de vestir e produzir moda tinham uma velocidade menor, que possibilitava, entre outras coisas, perceber diferenças evidenciadas pela possibilidade ou não de alguém usar moda, poder valer-se dela para, através da aparência, ser alguém. Antes a impossibilidade de reproduzir uma roupa de haute couture traduzia certa determinação socioeconômica, ou seja, quem podia pagar por sua confecção definia que poderia usar tal tipo de peça; a moda esforçava-se mais para diferenciar grupos, funções, postos clericais. Ainda que em um processo de desigualdade social, havia antes certa sensação de coletividade, de grupos, mas a partir da década de 1960 transformações nos modos produtivos, na distribuição e comércio ocorreram, mudaram a experiencia social do vestir. Muitos atores deste campo começam a pautar suas ações no consumo e na individualização desta experiencia.

Foucault (1995) propõe pensarmos o poder a partir de instituições atravessadas no campo que desejamos investigar, logo, aqui escolhemos o campo da moda em sua produção e transformações para olhar as práticas de vestir dos sujeitos. Seu método sugere que, ao fazer a pergunta "como se exerce o poder?", que no caso seria "que práticas de vestir são exercidas pelo sujeito?" ou "como você escolhe o que veste?", Poderíamos olhar para este campo a partir dos efeitos destas escolhas, dos exercícios que sujeitos e coletivos fazem. Portanto, acompanhar os processos dessas práticas no campo da moda, pode apontar os modos de construção de instituições, verdades e possibilidades de tensionamento neste mesmo campo. Lazzarato (2006) discute como se formam públicos de maneira a observar as condições de formação. No caso da juventude como portadora do ideal de novidade, pode-se 
pensá-la como consumidora padrão do sistema, que veio se transformando e extrapolou a regulação etária. Para o autor:

A subordinação do espaço ao tempo define um bloco espaço-temporal encarnado, segundo Tarde, nas tecnologias da velocidade, de transmissão, do contágio e da propagação a distância. Agora que as técnicas disciplinares estruturam-se fundamentalmente no espaço, as técnicas de controle e de constituição dos públicos colocam em primeiro plano o tempo e suas virtualidades. $\mathrm{O}$ público se constitui através de sua presença no tempo. (Lazzarato, 2006, p.75).

A juventude como modo de vida, expressão de vanguarda, teve sua invenção e ascensão nos anos de 1950/60. A moda antecipa este processo. As lojas passaram a oferecer o look completo, desde o sapato até a maquiagem; tudo isso envolvido por música própria para cada tipo de público (Laver, 1989 , p. 266). O cenário foi propício para que magazines se especializassem em formas atrativas para manter os clientes nos estabelecimentos a fim de fazê-los consumir cada vez mais. Um púbico ávido por novas experiências de consumo fomentou tais práticas.

Sant'anna (2008) e Mesquita (2008), sublinham que é a construção do sujeito que produz sua aparência e que, ao buscar nesta prática a superação autônoma de obstáculos, ele constitui o sujeito da moda contemporânea. O campo da moda, cotidianamente construído e desejado por este sujeito, torna impessoais suas criações. A noção foucaultiana de subjetividade fala de uma relação do sujeito consigo mesmo, em que até as relações de força tensionam-se em um si mesmo. A produção de subjetividade com vias de singularização envolve a experimentação, de modo muito solitário de suas sensações, necessidades, refletindo no corpo o que se quer, a ideia de um público passa pelo engolfamento desta experiência, capturando seu potencial criativo ali onde ele nasce. Nesta construção de públicos, que deseja uma moda "completa", que se oferece como resolução de suposta demanda para o vestir, parece não haver abertura à alteridade. A ideia de alteridade, de exercícios do sujeito, pode ser descrita como cuidados de si e podem ser pensados como práticas de liberdade, técnicas que produzem um sujeito que passa a assumir o que do mundo lhe faz sentido e vincula-o ao espaço-tempo em que vive, possibilitando uma responsabilização do que faz e do que é. Dizer "sou assim, deste modo" e "faço isto, ou aquilo", "visto-me desta forma" é manifestar cuidados para consigo, modos de afirmar uma liberdade e uma ética da existência; é produção de subjetividade que implica a invenção de um saber do sujeito sobre si. Em discussão sobre modos de subjetivação a partir da ideia dos estudos culturais Hennigen e Guareschi (2006) afirmam que:

as práticas culturais ou práticas de significação tentam fazer valer certos significados, particulares de um grupo social, sobre todos os outros: os jogos de poder estão sempre implicados. As práticas culturais são interpelativas, buscam dizer ao sujeito quem ele é, como deve ser, o que deve fazer; inventam categorias das quais se ocupam, criam referentes que se constituem como marcadores pelos quais os sujeitos passam a se reconhecer e posicionar. Contudo, para que isso aconteça, é preciso que tais significados adquiram o estatuto de verdade para o sujeito. (Hennigen; Guareschi, 2006, p.60).

O poder da moda está na própria formulação do desejo de vestir uma novidade. Sobre o aprimoramento e, por que não, requinte dessa ferramenta, Hur (2013) conclui que "decorre-se assim a sofisticação de tecnologias de governo, como a publicidade, e a modulação das formas de ser, de se afetar e 
de se auto-governar." (p.13). As tecnologias de governo a que Hur se refere, são de ação no pensamento, na formulação do desejo dos sujeitos. Estes desejam o governo do sistema, que nos mantém em uma trama de ilusões impossível de despertar, cujas brechas precisam ser conquistadas, inventadas, produzidas.

Neste contexto de alienação desejada, de afirmação de escolhas efêmeras de práticas do vestir, escolho produzir um espaço, um grupo que ocupa um tempo na vida de pessoas, em que a roupa passa a ser a desculpa para o convívio.

\section{O Projeto}

Pensando ser impossível fugir de uma operação que envolvesse a ideia de consumo, escolho a modalidade escambo como mote para produção do Projeto chamado Brechó de Troca. O Brechó de Troca nasce do incômodo com os modos acima descritos de operar da moda, e com a efemeridade de suas imagens. Percorrer o caminho da construção desta ideiaação é poder olhar para as práticas do vestir que produzem o sujeito do contemporâneo. Acompanhar os jogos de poder que a moda vem protagonizando é também acompanhar o que pôde ser feito de diferente, de singular, de potente neste processo. Em uma atenção que vai do macro, dos processos de vêm fazendo da moda o que ela é hoje, ao micro, em um olhar sutil, justifico meu incômodo com os modos de produção de subjetividade junto às práticas do vestir, à produção de imagens de moda e às memórias que advém desses processos.

O grupo acontece quase mensalmente (com recessos nos meses de janeiro, fevereiro e outros no ano de 2014) desde 2009. Convido virtualmente pessoas cadastradas, em um enviador de e-mails e em site do Projeto, através de um flyer de divulgação. Cada pessoa traz entre 5 e 20 peças de roupas ou também acessórios, objetos de seu guardaroupa, ou mesmo de terceiros, em desuso. Estipulo a limitação de vagas a fim de dar uma moldura, e fazer possível a operação de uma metodologia que não tenda ao caos e a repetição da rapidez como expressão da efemeridade do marcado de moda. Todas sentamos em círculo e faço uma abertura em dois tempos: em um deles trago uma fala sobre assuntos da cultura de moda, denúncias de práticas abusivas do mercado, e outros conteúdos afins (e, por vezes, trago convidadas para falarem sobre seu trabalho no campo da moda em primeira pessoa); no segundo momento explico ao grupo como funcionará o encontro.

Cada pessoa é convidada a apresentarse livremente e também a falar algo sobre cada peça que trouxe. As falas são livres e oportunizam a existência da roupa/acessório para além de um objeto desencarnado de significações de uma arara ou vitrine. São relatos mais ou menos pessoais, mas que sempre possibilitam às demais parceiras um contato alongado, pessoal e afetivo com a experiência do consumo. Há pessoas que se estendem na apresentação contando histórias que viveram com a roupa ou seus desafetos com quem lhes presenteou; mas há também quem limita-se a uma fala descritiva do objeto, seja por timidez ou pelo modo como a roupa engendra-se em seu guarda-roupa.

$\mathrm{O}$ único critério para as barganhas e trocas (que é explicado no segundo momento da abertura) impõe-se sobre peças com mais de um interessado. Quando a manifestação de interesse por algo se mostra de modo efêmero através de várias pessoas, peço que o objeto fique em um espaço (quase metafórico) que denominei de limbo. Peço que estas roupas sejam trocadas no final do encontro, depois de todas as outras possibilidades de trocas diretas. Com esta prática pretendo suspender o afã, a ansiedade própria do consumo de moda, e também oportunizar o atual dono da peça uma reflexão de como agir, com quem trocar ou mesmo se de fato deseja fazer o escambo. É na experiência de solidão que as memórias da imagem de sujeito, que se subjetivou por este item de moda que o interesse ao olhar para os processos coletivos pode se dar. O limbo foi 
pensado metodologicamente após um encontro em que participantes puderam, após o término, me retornar certo desconforto no limite dado a elas por outra participante que se mostrou afoita na barganha de um colar. A antiga dona privilegiou a troca com uma pessoa só e não interferi na ocasião, mas devido tal demonstração de desconforto entendi ser necessária invenção de dispositivo metodológico para suspender o ímpeto da não democratização do acesso à barganha nos grupos.

Depois da abertura, apresentações, negociações e trocas, cada parceira guarda seus novos itens e, eventualmente peças que trouxe e não trocou, paga um ingresso de participação (que inclui repasse de aluguel ao local, um pequeno lanche e, quando o número de pessoas é expressivo, meus honorários) e despede-se. A ideia de um fechamento parece reduzir o encontro a um determinismo terapêutico de que se deseja fugir. Os processos que vem ocorrendo ali não se resumem a terapêuticos, tanto pelas diferentes dimensões de acontecimentos que produz, como por uma simples despreocupação de afiliação de abordagem: pretende-se na abordagem ético-estética-política, da Psicologia Social, ocupar-se dos afetos que se produzem no processo e seus efeitos no Projeto.

Foram dezenas (quase centenas) de encontros ao longo de 10 anos. A publicização trocou de rede social, de Orkut para Facebook, de e-mail pessoal para institucional, de flyer improvisado para um supervisionado por designer, de preocupação com divulgação na mídia para o acolhimento parcial de interesse da mídia de massa. Atualmente os flyers de divulgação contém imagem que faz alusão ao tema da abertura, por exemplo. Antes a imagem era genérica ou, como nos primeiros encontros, repetia uma imagem produzida especialmente para este material que tinha mãos carregando uma pilha de roupas. A circulação desse material buscava a amplitude de acesso através do envio a grandes mídias, sejam jornais de grande circulação, jornalistas, mas também para a mídia de moda em expansão nos anos 2010: os blogues de moda. Mas a crescente preocupação com o caráter ético-político do acesso ao Projeto passei a enviar menos a esses veículos, e mais a grupos independentes, para movimentos sociais, ONGs, órgãos públicos e colegas, como forma de afirmar a um posicionamento do campo da Psicologia Social para as questões que o Brechó se propõe a visibilizar. Os locais escolhidos para sua execução privilegiaram fácil acesso, privacidade da sala e o acolhimento de proprietários e gestores para com o Projeto. O Projeto é itinerante, mas costuma ficar bastante tempo em que cada local. $\mathrm{O}$ primeiro foi um espaço interdisciplinar que já conhecia, depois foram mais 13, alguns durando apenas um encontro e outros mais de um ano. Ainda tiveram outros pontuais, feitos por pedido onde leu-se uma demanda, seja de empresas ou de projeto pessoal, mas sempre respeitando os critérios descritos.

\section{Resultados}

O Brechó de Troca viveu e acolheu uma infinidade de histórias nestes 10 anos de existência. Em projeto de pesquisa em Programa de Pós-Graduação algumas delas puderam ser reescritas. O trabalho olhou para a memória do Projeto com objetivo de analisar a potência de resistência às práticas empobrecidas de vestir do contemporâneo. Reconstruí o calendário de eventos organizando um patchwork de elementos de memória, que envolveram $\mathrm{o}$ resgate de fotografias, flyers de todos os encontros, anotações diversas. A ideia nunca foi recriar situações, mas usar o corpo-memória de pesquisadora para analisar afetos no encontro com o mundo, com o presente de atuação do Projeto.

Nos capítulos que se seguiram foi analisado o modo como o Brechó valeu-se da relação com a mídia, como engendrou na cidade a escolha/encontro dos/nos locais em que ocorreu e desdobrou a noção de troca. Como citado na construção metodológica, o 
posicionamento de publicização, de acesso às parcerias, foi se recriando na medida em que se entendeu que o trabalho se perde quando a mídia faz uma interferência abusiva. $\mathrm{O}$ cuidado com a produção dos flyers foi tomado após encontro que superlotou (Soares, 2016, p.51). A clareza, que visa a afetação, precisou ser mantida sob cuidado mensal. A partir de 2017, os encontros passaram a ser agendados no ano, de modo a facilitar a organização de quem interessa-se por ele. Recebi inúmeras mensagens de agradecimento e a comunicação virtual prévia foi simplificada com tal iniciativa: eram muitas mensagens perguntando quando e como os grupos ocorrem, e a agenda anual denota o cuidado em resposta objetiva. Mas tantas outras questões não couberam nesta escrita.

Os 14 locais públicos foram descritos por letras em um dos capítulos de dissertação (Soares, 2016), mas na verdade foram mais desde então, pois cada vez mais o trabalho ganha corpo de campo da Psicologia Social e são feitos pedidos de execuções sob diferentes demandas. Algumas histórias pontuais não foram possíveis de serem descritas dada a urgência do recorde de pesquisa e do calendário acadêmico de banca.

Duas das mais citadas pelas parceiras são a dos casacos cor-de-laranja e o sapato preto. A história dos casacos laranja envolveu o inusitado do encontro de dois casacos idênticos, ainda que tão singulares em seu modelo (tanto pela cor como pelo tecido veludo cotelê). Duas parceiras levaram suas peças e, entre elas, cada uma trouxe um destes casacos; porém faltaram casacos para troca, pois três parceiras interessaram-se por eles. Durante alguns encontros a pessoa que não pode ter um dos casacos falou sobre a situação, mas continuou frequentando $o$ Projeto, fazendo suas trocas e ainda me convidou para um escambo em sua residência. $\mathrm{O}$ caso do sapato preto envolve o modo como uma pessoa demonstra interesse em uma peça: uma parceira levou um sapato de plástico preto de modelo e marca nacionalmente conhecido e outra parceira teve uma reação efusiva pedindo para trocar, pois havia encomendado tal modelo, de mesma cor de tamanho, em uma loja especializada. Ela levou o sapato e me referiu recentemente que o tem no guarda-roupa ainda, por anos.

Além das histórias nos encontros é importante sublinhar a relevância do uso da palavra parceira para nomear as pessoas que se envolvem com o Brechó de Troca. Passei a usá-la em meados de 2014, durante o processo de pesquisa de mestrado, quando coloquei em análise a potência de atos de sustentação de diferentes atores que vem compondo este trabalho. Estas pessoas são tantos as que participam dos encontros, mas também criadores de projetos parceiros, donos e gestores dos locais que acolhem o Projeto, colegas que multiplicam a ideia, colegas que se colocam em diálogo crítico problematizando constantemente novas ideias que tenho para sua continuidade e mesmo orientadoras de mestrado e doutorado.

Ainda é preciso dizer que a escrita em site e página em rede social costura o tempoespaço entre os encontros. A escrita passou a ser um veículo tanto de reflexão crítica do próprio trabalho (muitas vezes não publicitado), mas de posicionamento éticoestético-político acerca de notícias, atos, processos do sistema da moda das quais a Psicologia Social pode e deve ter. Ela compõe uma escrita do próprio trabalho na medida em que o inscreve no sistema, desconstituindo um espaço dentro-fora que a Psicologia historicamente tenta produzir.

\section{Considerações Finais}

Se na loja a memória das roupas é algo oculto, o Brechó de Troca oferece-se como Projeto que convida à produção de subjetividade, em uma perspectiva foucaultiana, de experiências de práticas do vestir singulares, plurais, coletivas; permite um espaço-tempo para isto. A discussão pósestruturalista da Psicologia, de abordagem ético-estética-política, entende que a produção de subjetividade se dá incessantemente na 
cultura, e que o modo como esse processo se dá, mais ou menos coletivo, ciente ou não de seu lugar no mundo, se dá sob o regime de jogos de verdade específicos aos contextos dessa produção. Por exemplo, quem nasce e é educado sob a lógica de certo discurso de consumo onde roupas são adquiridas em lojas de shopping center, constitui-se sob tal verdade. $\mathrm{O}$ esforço de criação, de exercícios de si ao espelho, ao olhar do outro, precisa ser incessante para produzir ruptura em tal lógica. Uma Psicologia Social que não localiza tais jogos e tensões trabalharia a lógica do consumo de moda sob a ótica do esforço pessoal de não consumo, desconsiderando a construção histórica na qual estamos inseridos. No limite ao consumo, no convite à fala, no convívio do grupo, na escrita ampliada, o Brechó de Troca convida parceiras a encararem o sistema da moda como algo que segue buscando a captura do desejo, encararem nossa pouca possibilidade de inferência nesta lógica. Entretanto, com o esforço de persistir produção de brechas para a produção de subjetividade em um modo coletivizado e carregado de produções de memórias.

Somos seres vestidos: não há local público (urbano e colonizado) em que não nos coloquemos sob o regime de verdade do vestir. Mais do que adequação da tensão entre dress codes e o despudor do nu artístico e transgressor, a roupa pode produzir muitas experiências singulares quando pensada como elemento de produção de subjetividade. Como cultura material, que se insere em um tempoespaço de práticas localizadas, a roupa pode descolar-se da lógica efêmera da moda se mais e mais reflexões de diferentes campos analíticos, incluindo aqui a Psicologia Social, inventando outros modos de estar no mundo. Diferentes práticas podem coabitar em um esforço de resistência ético-estética e política ao consumo efêmero. Nos parcos projetos que se dispõe a tal resistência, que posição a Psicologia pretende afirmar?

Longe de mostrar-se como solução, para a maciça produção que o mercado impõe freneticamente, não vislumbro o Projeto como uma ideologia a ser homogeneizada. Mas busca-se uma inscrição de histórias que se inventaram em sua trajetória. Se a escrita da história da moda até hoje se mostrou em muitos momentos cruel e efêmera, a Psicologia Social pode, com suas ferramentas, olhar com disposição a afetação de projetos como o Brechó de Troca, inventar novos modos de trabalhar com a roupa e as práticas do vestir. Dispor-se a problematizar o que é o consumo e entender que o escambo é uma de suas práticas, porém menos ligeira e mais próxima de experiências em grupo.

O que falta para o campo a Psicologia Social, problematizador de práticas institucionalizadas e produtor de práticas de resistência, dispor-se a invenção de projetos junto ao sistema da moda? Todos estamos vestidos no campo da cultura, e todos nos comunicamos como modo de escape a barbárie. Escutar as expressões da cultura em um ato de sustentação das trocas é afirmação ético-estético-política das diferenças, do lugar da roupa no mundo dos afetos e não do desapego desimplicado. O Brechó de Troca dispõe-se, como apontaram algumas reflexões levantadas na dissertação citada, a abrir mais este campo, em uma abordagem ético-estética e afirmando-se politicamente resistente as lógicas vigentes de consumo de moda, a ser não apenas campo para a Psicologia Social. Dispõe-se também, em suas experiências descritas aqui e em outros textos, como vetor na tensão, força que disputa lugar, e que convida psicólogos (as) curiosos (as) a trazer a discussão, do que já se faz em Psicologia, mas também pela perspectiva do sistema da moda em suas práticas. Considerar o que já existe, mas que não fora visto sob tal ótica, para dar potência a escuta do social. Alguns dos autores citados neste texto são amplamente discutidos pela Psicologia em diferentes épocas; entretanto pouco de suas obras sobre a moda foi explorada. A experiência do Brechó de Troca aponta para que se possam rever escutas e práticas da Psicologia, e particularmente da Psicologia Social, valendo- 
se de problematizações ignoradas outrora, mas que são familiares ao olhar problematizador. Reler Lipovetsky para ler o que a roupa pode em um projeto na Assistência Social, considerar o Sistema da Moda de Roland
Barthes para discutir as mídias de moda e como elas são produtoras de subjetividade são algumas das muitas aberturas que o Projeto aqui descrito entende serem pontos de partida possíveis para novas intersecções de campos.

\section{Referências}

Barthes, R. Sistema da Moda. (1979). São Paulo: Ed. Nacional: Ed. da Universidade de São Paulo.

Bourdieu, P., \& Delsaut, Y. (2001). O Costureiro e sua Griffe: contribuições para uma teoria da magia. Educação em Revista, s/v(34) 7-66.

Calanca, D. (2008). História Social da Moda. São Paulo: Editora Senac São Paulo.

Figueiredo, L. C.; Santi, P. L. R. (2008). A Psicologia, uma (nova) introdução: uma visão histórica da psicologia como ciência. São Paulo: EDUC.

Flügel, J. C. (1964). Psicologia Del Vestido. Buenos Aires: Editorial Paidós.

Foucault, M. (1995). O sujeito e o poder. In: H. Dreyfus, \& P. Rabinow, Michel Foucault, uma trajetória filosófica (pp. 231-249). Rio de Janeiro: Forense Universitária.

Freud, S. (1930). O Mal-Estar na Civilização. (Obras psicológicas completas). Rio de Janeiro: Imago Editora.

Hennigen, I; Guareschi, N. (2006). A subjetivação na perspectiva dos estudos culturais e foucaultianos. Psicologia da Educação, s/v(23), 57-74. Recuperado de http://pepsic.bvsalud.org/scielo.php?script= sci_arttext\&pid=S141469752006000200004\&lng=pt\&tlng=pt.

Hur, D. (2013). Da biopolítica à noopolítica: contribuições de Deleuze. Lugar Comum, $s / v(40), 201-215$. Recuperado de http://uninomade.net/lugarcomum/40/

Laver, J. (1989). A roupa e a moda: uma história concisa. São Paulo: Companhia das Letras.

Lazzarato, M. (2006). As revoluções do Capitalismo. Rio de Janeiro: Civilização Brasileira.
Leventon, M. (2009). História ilustrada do vestuário: um estudo da indumentária, do Egito antigo ao final do século XIX, com ilustrações dos mestres Auguste Racinet e Friedrich Hottenroth. São Paulo: Publifolha.

Lipovetsky, G. (1989). O império do efêmero. São Paulo: Companhia das Letras.

Maffesolli, M. (2010). No Fundo das Aparências. Petrópolis, RJ: Vozes.

Mesquita, C. (2008). Biopolíticas da Aparência. Anais $4^{\circ}$ Colóquio de Moda. Disponível em:

<http://www.coloquiomoda.com.br/anais/C oloquio\%20de\%20Moda\%20$\% 202008 / 42862$.pdf > Acesso em: 20 set 2018.

Roche, D. A. (2007). Cultura das aparências: uma história da indumentária (séculos XVII - XVIII). São Paulo: Editora Senac.

Sant'Anna, M. R. (2009). Teoria de moda: sociedade, imagem e consumo. São Paulo: Estação das Letras e Cores.

Sant'anna, M. R. (2005). Criação do Prêt-àPorter, História, Contexto e Critica. In Anais $1^{\circ}$ Colóquio de Moda (48-67). Ribeirão Preto, São Paulo/Brasil. Recuperado de http://www.coloquiomoda.com.br/anais/Co loquio\%20de $\% 20$ Moda $\% 20$ $\% 202005 /$ COMUNICACOES-R Z.pdf

Sant'anna, M. R. (2008). Poder e Aparência Incontornáveis questões da teoria de moda. In Anais $4^{\circ}$ Colóquio de Moda (). Novo Hamburgo, Rio Grande do Sul/Brasil. Recuperado de http://www.coloquiomoda.com.br/anais/Co loquio\%20de\%20Moda\%20$\% 202008 / 42044 . \mathrm{pdf}$

Soares, H. B. (2016). Brechó, brecha, break : 
Produção de subjetividade pelas práticas do vestir no Brechó de Troca: novos campos para a Psicologia Social

produção de subjetividade pelas práticas do vestir no brechó de troca (Dissertação de mestrado, Universidade Federal do Rio
Grande do Sul). Recuperado de

https://lume.ufrgs.br/handle/10183/157636

\section{Dados sobre os autores:}

- Helena Soares: Doutoranda em Psicologia Social e Institucional da UFRGS, onde também se formou mestre. E psicanalista, e tem experiência em pesquisa em sociologia econômica na área de economia criativa. Criou o Brechó de Troca em janeiro de 2009. 